\title{
O SUL DA MINHA VIDA: ANGOLANIDADE, RAÇA E IDENTIDADE EM O PLANALTO E A ESTEPE, DE PEPETELA
}

\author{
O SUL DA MINHA VIDA: RACE AND IDENTITY ISSUES IN 0 \\ PLANALTO E A ESTEPE, BY PEPETELA
}

\author{
Renata Cristine Gomes de Souza' \\ [https://orcid.org/0000-0001-7830-4571] \\ DOI: 10.30612/raido.v15i37.13397
}

RESUMO: O romance 0 planalto e a estepe, de Pepetela, foi publicado em 2009. Nesse romance temos como pano de fundo a luta pela de independência de Angola e os anos que se seguiram com a construçăo/restruturaçăo do país. Nesse livro há a apresentaçâo de espaços que nunca antes foram visitados nas obras do autor, como a Mongólia, e personagens com trajetórias diversas das antes vistas na literatura do autor. Com a análise desse romance, trataremos de algumas questóes que envolvem a formaçáo da identidade e a construçấo social do indivíduo, a partir da trajetória das figuras ficcionais, seguindo o eixo principal, que é a formaçăo da identidade do protagonista, Júlio. Problematizando-se sentidos de colonialidade e raça, com este estudo pode-se concluir, como principal resultado, que a raça foi um fator determinante na construçấo da identidade social no contexto histórico ao qual se reporta esse romance de Pepetela.

Palavras-chave: Identidade; Preconceito; Angolanidade.

ABSTRACT: The novel $O$ planalto e a estepe, by Pepetela, was published in 2009. In this novel we have as background the fight for the independence of Angola and the years that followed with the construction/restructuring of the country. In this book there is the presentation of spaces that have never been visited before in the author's works, such as Mongolia, and characters with different trajectories from those seen before in the author's literature. With the analysis of this novel, we will deal with some issues involving the formation of identity and the social construction of the individual, starting from the trajectory of the fictional figures, following the main axis, which is the formation of the identity of the protagonist, Julio. By problematizing the meanings of coloniality and race, the main conclusion of this study is that race was a determining factor in the construction of social identity in the historical context to which this novel by Pepetela refers.

Keywords: Identity, Prejudice, Angolanity.

O romance $O$ Planalto e a Estepe, de Pepetela, foi publicado em 2009. Esse é mais um romance do autor que tem como pano de fundo a luta de independência angolana e a construçăo/restruturaçăo do país.

1 Mestre em Estudos de Literatura pela Universidade Federal Fluminense (UFF), cursa o Doutorado em Literatura Comparada na mesma instituiçăo. 
A narrativa conta a história de amor de Júlio e Sarangerel que tem seu início no apogeu da Uniăo Soviética. Júlio é um jovem revolucionário angolano, repleto de ideais que vai estudar em Moscou convicto e disposto a levar preceitos socialistas para a sua pátria. Sarangerel é uma jovem nascida na Mongólia, também estudante de economia, que partilha dos ideais de Júlio. A uniăo desse casal, que poderia ser um símbolo do internacionalismo das naçóes socialistas mostra-se impossível de ser concretizada, pois, nesse momento, tudo perpassava a esfera política, até mesmo as relaçóes amorosas.

O planalto e a estepe, romance com um tom biográfico, é baseado na vida dos amigos do autor, Suren e Piricas, aos quais o livro é dedicado. A ligaçâo com fatos reais é sugerida pelo próprio Pepetela na "Nota prévia":

A estória aconteceu.

No essencial, mais ou menos como se conta.

As personagens săo de ficçăo.

Todas.

Mesmo aquelas que fazem lembrar alguém (PEPETELA, 2009, s/p.)

Náo só a história de amor contada em $O$ planalto e a estepe tem uma forte ligaçăo com a realidade, como todo o pano de fundo histórico e social apresentado na narrativa. Esse cenário histórico nos leva a repensar o fim do período colonial, as lutas de libertaçâo e a implantaçâo do socialismo em Angola e nos países amigos. As condicionantes históricas e político-sociais sâo as definidoras do enredo da trama, e podemos dizer que sâo essas condicionantes que movem a vida de Júlio. Elas săo delimitadoras no processo da construçăo da identidade do narrador.

Há no romance uma série de críticas a questôes ligadas à colonialidade, como a vida do homem branco em Angola, o racismo, as lutas de independência e a implantação do regime socialista. Esta última questăo se estenderá a outras naçôes africanas como o Senegal. Percorremos, com a leitura do romance, diversos lugares que têm sua singularidade para a luta angolana, como a Rússia e a Mongólia, entre outas, e também vamos à lugares fulcrais para a expansâo e a solidificaçăo do socialismo.

No romance, a utopia se faz presente desde o primeiro questionamento do protagonista, mas é com a sua ida para Moscou que esse discurso tem mais presença na narrativa. Lá ele faz amizades com outros rapazes africanos, sobretudo com Jean-Michel. E é a partir dessa convivência e das razóes políticas que impossibilitam o seu romance com Sarangerel, que ele desenvolve uma opiniăo crítica a respeito da nova fase que o país lutava para alcançar.

A insatisfaçăo que Pepetela carrega em relaçăo ao falso socialista é bem marcada em suas obras e em seu discurso, assim como quando é interpelado a respeito da situaçăo política de seu país. Os romances do autor apresentam uma forma de veiculaçăo de seus ideais. Logo, para Pepetela:

defender a luta pela independência era para criar uma sociedade mais justa e năo para substituir uma elite (colonial) por outra. E aconteceu que uma classe dominante substituiu a outra classe dominante. O capitalismo selvagem que temos em Angola nâo leva a lado nenhum, tal como dantes năo levava. (PEPETELA, 2002 apud DUTRA, 2011). 
Essa fala do autor dialoga com o romance em estudo, pois nele transparece essa insatisfaçâo ao reconstruir a trajetória que fez com que o país chegasse até esse capitalismo selvagem. $O$ retorno ao passado, registrado em $O$ planalto e a estepe, serve como artifício para que năo esqueçamos que esses seus ideais permanecem, pois, apesar de a Angola por ele sonhada nâo existir, há muitos que resistem em sua luta. A história de Júlio acompanha o fracasso da nova política em gestăo, mas, traz personagens que estâo contra essa corrente que leva Angola ao declínio. Sobre o autor angolano e seus ideais, Mia Couto afirma:

Angola foi mudando, experimentando a ferro e sangue os interesses de quem troca naçôes como fonte de lucros. De todas as vezes que fui encontrando Pepetela fui sentindo como o seu orgulho se ia convertendo em mágoa, a esperança se ia, de quando em quando, confrontando com a desilusáo. Como o tempo parecia desutopiar geraçōes. Mas ele, o Pepe, é a geraçăo de si mesmo. Há nele qualquer coisa que resiste, como se fosse o caroço de uma alma mais profunda, que năo esmorece nem se esgota. (COUTO apud CHAVES; MACEDO, 2009, p. 84).

Pepetela resiste em seu discurso. Por tal razâo, ele traz, na trama, na construçăo de seus personagens e, principalmente, no desfecho das diversas histórias que compóem o romance, o indício de que a esperança se deve manter acesa. É o reflexo dessa resistência que se vê na construçăo dos personagens e com ela há a possibilidade de mudança, a possibilidade de voltar-se novamente para o Sul. No presente trabalho trataremos de questôes relativas a raça e identidade, partindo de uma análise do personagem principal do romance e de seu universo de percepçâo.

\section{RACISMO E IDENTIDADE}

Na obra em análise, Pepetela parte de seu conhecimento do espaço representado para a criaçấo das tensôes relacionadas ao racismo presentes na obra, como podemos observar no seguinte relato:

Vivi em Benguela, a melhor cidade nesse aspecto [racismo]. Mas quando fui estudar para o Lubango senti a diferença. Sobretudo na segregaçáo racial. Via como os meus colegas negros eram tratados. [...] Benguela era uma cidade muito particular. Metade da populaçáo era mestiça, estabelecia relaçóes. Na escola tinha companheiros de todas as cores. Havia racismo, claro, mas havia uma maior integraçăo da populaçăo. As outras cidades eram piores. A maioria da populaçăo do Lubango era branca. Passava férias no Huambo e íamos em grupo para a piscina. Năo nos deixavam entrar. Diziam: 'Tu e tu podem, os outros năo'. Eram mestiços ou negros. (PEPETELA, 2011. s/p.)

A descoberta de como a raça influenciava a vida e os direitos das pessoas em Angola é feita pelo autor e pelo protagonista no mesmo ambiente, ou seja, há aqui uma linha horizontal que liga as experiências de ambos. Assim há a materializaçáo das palavras de Rita Chaves, que afirma que "O apreço pela memória [...] surge em jogo com o conhecimento que parece resultar da experiência." (CHAVES, 2004, s/p). Um exemplo disso é essa descoberta do racismo, que; para ambos; se dá quando saem de sua comunidade familiar e começam a conviver com outros grupos de pessoas, na escola. 
Júlio é descendente de portugueses, pai lusitano e mâe branca já nascida na Huíla. Natural do Lubango, onde passa a infância e o início da juventude, ele foi criado junto às crianças negras da vizinhança e aos filhos dos criados que viviam nas cubatas. Mesmo tendo uma posiçấo diante da comunidade ali instaurada e diferenciada da de seus amigos, ele cresce sem notar a diferença entre eles. Assim que inicia os estudos, ele se dá conta do abismo sociorracial que os separavam, entăo percebe que a segregaçăo, que ali havia, se dava por vários fatores que se relacionam a esfera econômica, racial e cultural.

Até entâo, a segregaçáo social causada pelo colonialismo năo era notada pelo personagem, que aos poucos passa a ver como naquele momento e naquele lugar o homem negro vive à margem. Desse modo ele passa a observar esse processo que se dá durante o período colonial, no qual o homem negro angolano é subalternizado por parte da populaçăo portuguesa levada para Angola, que tiraram as riquezas da terra, estabeleceram um modo de vida que julgavam superior e exploravam a força de trabalho dos nativos. É através do olhar crítico de Júlio que o leitor se depara com algumas cenas de racismo abordadas no livro, as quais ilustram bem a estratificaçăo social, econômica e racial do período colonial.

O pensamento racista da escola nâo molda a mente de Júlio. O que ocorre é o contrário, a impossibilidade de todos terem acesso à educaçăo e a vida em comunidade faz com que o protagonista passe a contestar a escola e as outras instituiçóes. No país multirracial que Salazar dizia ser Portugal, só os pertencente a uma raça tinham direitos. A constataçâo do racismo existente naquela comunidade é essencial para o desenvolvimento da identidade de Júlio, pois aquele é o primeiro momento em que ele passa a questionar a sociedade, a religiăo e as instituiçôes. Desde entăo, ele passa a ter uma ótica que o guiará durante a vida.

O protagonista tinha um comportamento diferente das outras crianças brancas, ensinadas a segregarem-se em suas comunidades. Ele năo tinha vontade de se juntar aos novos colegas do colégio, como fora sugerido pela irmá, que gostaria que ele se afastasse das crianças negras. Ele năo vê razâo para se afastar de seus verdadeiros amigos. Essa pressáo feita por Olga, a irmă mais velha, é repetida pelos jovens brancos da regiăo e pela polícia, pois, no sistema colonial, era impossível que um jovem branco andasse cercado de negros:

E quando nos viam, as meninas riam, lá vai o branco mapundeiro com os seus negros. Poucos eram os negros que se aventuravam ir ao Picadeiro no domingo. Um branco com amigos negros era um branco estranho, malvisto. [...]. Um dia dois homens com chapéu cinzento na cabeça encostaram-me a um canto do liceu. Entăo és tu o bolchevique amigo dos pretos... [...] Mas eu náo era amigo dos pretos por serem pretos, nem via bem as cores nem as cores têm importância. Era amigo dos meus amigos, isso sim. (PEPETELA, 2009, p. 21).

Nas "terras multirraciais lusitanas", em que o homem negro deveria negar sua cultura e adquirir a imposta pelo homem branco, a aproximaçăo de pessoas de raças distintas era malvista. Desse modo, o plano do colonizador de imposiçăo cultural consegue ser bem-sucedido, pois o único espaço para o negro dentro da cultura branca era o lugar de servidăo.

Ao analisar a situaçáo social do período de lutas pela libertaçáo, grosseiramente pode-se afirmar que temos duas partes bem divididas e equidistantes da sociedade, 
na qual uma parte enriquece em vias da subalternizaçăo da outra. Esse processo de subalternizaçăo se dá por meio da apropriaçáo da terra do outro, como no caso de Angola, e da imposiçăo de uma cultura. Essas açóes săo, antes de tudo, determinadas por um extremo racismo extrínseco. Em razáo desse racismo extrínseco, os colonialistas brancos acreditavam que os povos negros das colônias năo possuíam aspectos como honestidade, inteligência e coragem, por isso deveriam ser tratados de forma diferente, nesse caso, quase animalizada (APPIAH, 1997, p. 33).

Segundo Boaventura de Sousa Santos, Portugal reproduzia sobre suas colônias o ato subalternizador, ao qual também eram submetidos os seus naturais quando se tratava da relaçấo de Portugal com as potências europeias (SANTOS, 2003, p. 99). Portugal, o país subalterno da Europa, repetia o ciclo de subalternizaçăo em sua relaçấo com os habitantes das colônias. A humilhaçăo e a exploraçăo do homem negro da colônia era uma forma de engrandecer o homem português naquela sociedade, pois, como sugere Pepetela no romance: "O homem só gosta da diferença, sobretudo a que o favorece" (PEPETELA, 2009, p.22). Assim, diferenças cultural e racial eram usadas pelos colonizadores para a valorizaçăo do homem branco português e a diminuiçâo do negro africano.

O racismo extrínseco, aquele que julga haver distinçōes morais entre membros de raças diferentes, serâo definidores na trajetória de Joăo e Job, amigos de infância de Júlio. Os dois personagens sâo filhos de Kanina, um criado da família Pereira, e fazem parte do grupo de amigos que partilham com Júlio a infância e a juventude. Os irmăos e o narrador sabiam que, por mais que crescessem juntos, chegaria um momento em que se separariam, porque, naquele lugar, a raça determinava seus destinos.

Como a educaçấo era destinada apenas às crianças brancas, os negros poderiam frequentar apenas a catequese, pois a adesâo ao catolicismo era vista pelo europeu como um ato civilizador. Job e Joâo eram obrigados pelo pai a ir à igreja, pois, para ele, aquele era um modo de os filhos adequarem-se às normas do poder vigente.

O romance elucida como o racismo estava enraizado naquela sociedade por meio da negaçăo do próprio homem negro ao outro de sua raça, ocasionada pela pressâo social que o diminui e também pela polaridade de poder econômico. Outras cenas, que trazem esse racismo já estabelecido na sociedade, tratam da mecanizaçăo do homem negro, ao qual é negado pensar em diferentes possibilidades de vida, pois, para ele, cabe apenas uma alternativa de futuro que já é determinada para si, mediante a sua cor. Dadas essas ocorrências na obra, percebemos que o racismo extrínseco é tăo forte que seus agentes conseguem fazer com que as determinantes sociais do grupo dominante sejam absorvidas até mesmo pelas vítimas dos atos causados por esse preconceito.

O negro passa a reproduzir essa determinante social e nega o outro de sua própria raça. A negaçăo do negro a alguém de sua raça está presente na cena em que Júlio e Joăo, seu melhor amigo, văo ao prostíbulo. Lá, duas irmăs vendem o corpo para se manterem naquela comunidade que as coloca à margem por serem negras e mulheres, e elas só aceitam clientes brancos:

[...] tu podes, vem comigo. Ele năo, disse a irmă. O dinheiro é igual, disse o Joăo. Pois, mas a cor năo é, disse a irmá.

Racismo? De negro pra negro? [...] 
No fim perguntei, mas como recusas um da tua cor? Porque se um branco souber que me deitei com um negro, năo vai querer se deitar mais comigo. E os brancos é quem têm dinheiro.

Racismo, sim, mas dos brancos. (PEPETELA, 2009, p.18).

Assim, o leitor se depara com sujeitos que, presos pelo poder econômico, vivem de acordo com as determinaçôes de quem controla o sistema vigente, ou seja, os colonizadores. Como o dinheiro está nas mâos do homem branco, o único jeito que parece ser possível de sobreviver, até entăo, é cedendo às suas vontades.

As trajetórias de Job e Joâo também sâo marcadas por essas determinantes que envolvem o poder do homem branco na sociedade colonial. Joâo segue o destino que é determinado para o homem pobre e negro, que, por mais que tente ascender, é impedido por falta de oportunidade. Joăo é como o seu pai, que ensinou os filhos a obedecerem, trabalharem duro, respeitarem o trabalho e agirem de acordo com as determinaçóes de quem ter o poder, ou seja, aceitarem o destino seguindo o único caminho seguro que era possível de ser trilhado.

Job tem o comportamento contrário ao do seu irmáo e de seu pai. Ele se impóe diante das determinaçôes do poder vigente, porque era "avesso a ordens que năo entendesse" (PEPETELA, 2009, p.25). Seu modo de lidar com as instituiçōes e com a vida na colônia transforma-se no maior motivo de preocupaçăo para Kanina, porque, ao exigir o seu lugar e seus direitos, tornava-se um grande peso para o pai: Job era um terrorista, um inimigo do poder. Por mais que partilhasse das mesmas ideias de Júlio, a sua cor năo permitia que ele pudesse questionar o sistema de submissăo, logo, aos dezesseis anos, ele, um rapaz que apenas lutava pelos seus direitos, é executado como terrorista.

Todo esse período marcado por um discurso racialista, ou seja, aquele que qualifica o indivíduo pela cor de sua pele, acompanhado de intenso racismo extrínseco, faz com que o reconhecimento da raça negra seja uma das bandeiras do novo regime iniciado a partir da libertaçăo de Angola. Nesse sentido, a raça torna-se um fator crucial na identidade do homem angolano durante as lutas pela independência e em todo período pós-colonial.

\section{RAÇA E ANGOLANIDADE}

Muitas referências coincidem quanto a considerar a obra de Pepetela como buscando na história matéria para a ficçăo. [...] é na natureza dessa busca que me parece residir a diferença - eu diria até, a singularidade- dessa literarizaçáo dos factos históricos em Pepetela, năo pela cristalizaçăo de enclaves identitários mas pela mosaicizaçăo de identidades como fundadoras de um (novo) mapeamento nacional. (MATA, 2001. p.136).

A partir da trajetória de Júlio, o protagonista do romance, vemos uma nova identidade angolana a ser mostrada. Júlio, o narrador, é um homem branco, angolano que se enxerga como um homem de sua terra. Desse modo, 0 planalto e a estepe traz um narrador que ainda năo tinha tido voz e para o qual é difícil se dar voz, porque ser branco em Angola é quase sempre ser visto como o outro: o descendente do colonizador. 
Sabendo que os romances produzidos no período pós-colonial dăo voz ao homem que foi colonizado, homem silenciado durante todo período de colonizaçăo fica a dúvida se o romance quebra esse ciclo, já que o protagonista se encontra entre os dois lados, dividindo-se pela genealogia e pela ideologia. Por mais que, à primeira vista, pareça que essa postulaçâo năo é válida em $O$ planalto e a estepe, ao longo da leitura nota-se que nâo há uma ruptura desse processo. Júlio năo fala pelo homem lusitano e/ou pró colonizador ao construir seu discurso e nem fala pelo homem negro angolano, mas se coloca ao lado do homem negro angolano, às vezes, até abaixo, porque sabe que traz na sua cor a marca da diferença e a lembrança dos anos de exploraçăo. O narrador reconhece, na sua angolanidade branca, os privilégios que obteve na infância e juventude, mas, por escolha própria, contesta e se afasta gradativamente dessa comunidade que possivelmente o aceitaria. Para tal o autor constrói um discurso que faz com que o narrador, mesmo ao reconhecer suas diferenças e privilégios, esteja sempre ao lado do homem negro angolano. Júlio náo esmorece em momento algum, e segue lutando por aquelas pessoas e pelo país.

A partir da compreensáo dessa diferença de tratamento na sociedade, ele tenta compreender qual é o seu lugar e o de sua família nesse processo e, no fim dessa busca, chega a dois conceitos, o de colono e o de colonialista. A partir desses pressupostos, ele consegue enxergar com totalidade o complexo problema que a distinçáo racial trará para si durante seu percurso: “Colonialistas sâo os que querem que os africanos sejam sempre inferiores, sem direito de gente na sua própria terra" (PEPETELA, 2009, p. 23). Os colonialistas sáo representados pelos policiais, pela irmá Olga, pela escola e pelas redes de poder. Segundo Boaventura de Sousa Santos, esses colonialistas exerciam, em Angola, o colonialismo retroativo. Salazar afirmava a existência de uma pátria portuguesa multirracial, ou seja, era veiculada uma ideia de "colonialismo cordial", que de fato năo existia. Assim, o lusotropicalismo brasileiro foi apropriado por Salazar, que dizia que havia uma colonizaçáo branda e amigável. O governante afirmava que nâo havia uma metrópole e suas colônias, mas sim uma "naçăo lusitana que ia do Minho até o Timor" (SANTOS, 2003, p. 25), na verdade náo fazia valer essa igualdade, havia, sim, a clara divisâo entre colonizadores e colonizados.

Já os colonos faziam parte do grupo em que Júlio e a família se encaixavam, ou seja, eram as pessoas que viviam na colônia, amavam aquele lugar e que năo exploravam o homem negro. Notamos ainda que, ao mostrar que sua família é de colonos, o narrador coloca-se em um lugar de subalternidade, como podemos ver a seguir:

A diferença entre colono e colonialista durante muito tempo trabalhou a minha cabeça. [...]. Do outro lado da cidade. Uns miseráveis como ela contou, chamados pela gente da terra de chicoronhos, angolonizando a palavra colono. [...]. A família dela se mudou para este lado, teve campos náo cultivados, os que meu avô abarcava com o gesto largo do braço. Mas eram terras de ninguém e náo valiam nada. Por isso sempre foram chicoronhos pobres, pior, mapundeiros. (PEPETELA, 2009, p. 24-25)

Aqui o narrador se póe em lugar de subalternidade perante a sociedade colonialista. Sua família nâo era rica, năo tinha interesse em roubar a terra do outro, apenas tinha o intuito de viver bem naquela terra. Por tal razâo, o narrador vive em um constante esforço para evidenciar a sua afirmaçâo como um cidadăo angolano, sem considerar sua cor como um fator determinante. 
Quando se vê diante das instituiçóes e das leis morais, ele passa a conjugar o que aprende na escola com a sua vivência. Desse modo, começam a surgir os questionamentos, visto que a igreja e a escola pregavam um discurso que nâo era vivido ali. Seu professor de filosofia, e também Padre, é fundamental nesse processo de descoberta do sistema de poder vigente e suas falhas. A partir desse momento, Júlio muda a sua visăo de mundo, pois: “A cabeça cresce com as verdades que nela entram." (PEPETELA, 2009, p. 24)

Quando adulto, a questăo da cor da pele será uma barreira a ser quebrada, pois, naquele momento de luta pela independência de Angola, a raça era o principal modo de distinguir quem era o aliado e quem era o invasor. Portanto, a raça era uma forma de representaçăo da identidade do homem angolano. Segundo Stuart Hall "as identidades nacionais năo săo coisas com as quais nós nascemos, mas săo formadas e transformadas no interior da representaçáo"(2005 p.48), cabendo lembrar que, segundo o mesmo estudioso, "a raça é uma categoria discursiva e năo uma categoria biológica" (HALL, 2005, p. 62-63). A raça era, e ainda é, um elemento importante na construçăo da angolanidade, pois, ser negro é pertencer genuinamente à cultura e ao povo angolano, é trazer na pele sua identidade nacional. O branco passa a ser o estigmatizado e isso fará com que Júlio esteja sempre provando seu pertencimento à pátria e exigindo o seu lugar na luta por uma Angola livre e justa.

O narrador, que gostaria de atuar no campo de batalha, é mandado para a Uniấo Soviética para aprender mais sobre o socialismo, regime político que Angola adotaria assim que deixasse de ser colônia de Portugal. Essa imposiçăo - que é obrigado a acatar - de ir para a Rússia estudar economia. O protagonista gostaria de ter ficado no país, atuando na luta armada, mas em razăo de sua cor é enviado para a Rússia:

Os mais escuros iam combater. Receberiam treino militar na fronteira entre Marrocos e Argélia. Os mais claros tinham bolsas de países amigos, iam estudar para a Europa. A razăo era năo existirem condiçôes subjectivas para os mais claros participarem na luta armada. Traduzido por miúdos, os mais claros ainda năo eram suficientemente angolanos para arriscarem a vida na luta pela Naçăo, pelo menos havia dúvidas quanto a sua nacionalidade. E utilidade. De novo as raças a separarem os grupos. Fiquei desiludido, sobretudo humilhado. (PEPETELA, 2009, p.31)

Após retornar para sua terra, ele se torna um guerrilheiro, mas, embora seja atuante no combate, o personagem ainda carrega na pele a marca da dúvida. Para que essa diferença seja superada, ele faz uso de dois artifícios que irăo ser constitutivos da imagem que os guerrilheiros criarăo do novo coronel: um terá como base a cultura e a crença religiosa do povo angolano e, o outro, o colocará em um lugar de fragilidade/ subalternidade. $\mathrm{O}$ uso de um componente cultural nessa busca por reconhecimento é feito a partir da literatura oral, pois, ao mostrar que partilha das mesmas raízes culturais, ele prova seu pertencimento ao lugar. Partimos aqui da seguinte afirmativa de Stuart Hall: "'O "lugar"' é específico, concreto, conhecido, familiar, delimitado: o ponto de práticas sociais específicas que nos moldaram e nos formaram e com as quais nossas identidades estâo estreitamente ligadas." (HALL, 2005. p.72). O segundo artifício utilizado pelo personagem é a escolha de seu nome de guerra:

Precisava de ter um nome de guerra, como todos os guerrilheiros. [...] Antes que fosse os companheiros a escolher por mim, me resolvi a uma espécie de autoflagelaçáo simbólica. Pelo menos no Sul, era muito comum os colonos (sobretudo as suas 
mulheres) darem nomes de coisas aos homens ou rapazes que lhe serviam como criados. [...] Entấo eu lembrei de subverter esse pensamento, dando a mim mesmo, branco e de olhos azuis, o nome de um instrumento vulgar. Fiquei conhecido como o camarada Alicate. (PEPETELA, 2009, p. 129-139).

Ao escolher o nome de guerra, Júlio se coloca em um lugar de fragilidade. $O$ nome que poderia ser dado a um criado serve como uma metáfora para mostrar que ele era um homem a serviço da naçấo angolana.

Ainda quanto ao lugar de pertencimento, há na trajetória do protagonista um eterno retorno à África e ao seu Sul, nos planaltos da Serra da Chela. Em sua ida para Portugal, ele náo se aquieta enquanto náo volta para o seu lugar, e é essa mesma África que procura nas pessoas com quem partilha sua vida, seja em Coimbra ou em Moscou, com exceçăo de Sarangerel. Nesses dois lugares em que estuda, acaba por ter mais contatos com africanos, pois é essa África que procura nas pessoas, é nela que se sente bem. Estar em contato com essas pessoas é estar mais perto de sua terra. A visăo dos espaços que ele percorre é sempre diminuída em contraste com a beleza dos planaltos da Huíla. $\mathrm{O}$ único lugar pelo qual o personagem mostra uma grande afetividade, como a dedicada às serras do Lubango, é a floresta do Mayombe. Essa ligaçâo com a floresta em que esteve durante a guerrilha se dá por ser esse o território onde foi reconhecido como angolano através de sua luta. Assim, esse outro lugar de pertencimento é a terra onde ele renasce como cidadáo africano, pois só ali ele consegue realmente mostrar a sua angolanidade, lutando por ela e mostrando que pode dar a sua vida pela naçáo.

Depois da luta pela independência e de anos de serviço dedicados ao exército, sem se corromper, o personagem náo mais precisa provar que é um homem digno de dizer que Angola é sua terra. Vejamos no trecho a seguir:

Agora sobre a Serra da Chela. Podia ir visitar as estepes da Mongólia, ou as montanhas Altai. Ou até planar sobre as ilhas do Pacífico. Mas náo me apetece. Prefiro o Planalto a partir da Chela, as rochas de muitas cores, as falésias e suas cascatas, o verde dos prados, o campo das estátuas, o milho ondulando, as árvores retorcidas pelo vento. E pairar sobre a gigantesca fenda da Tundavala, fenda que aponta o deserto. E o mar. E aponta o sul, o grande Sul. O Sul da minha vida. (PEPETELA, 2009, p. 188)

Os anseios do povo mudam, as lutas săo outras e, novamente, vem a desesperança, mas, no fim de tudo, uma coisa é impossível de ser mudada: o amor de Júlio por seu país. Já mais velho, tempo de fincar raízes, ele se volta para o lugar que considera seu, sua terra, a terra para qual ansiou voltar. Mesmo com todos seus deslocamentos, a guerra, a perda e o reencontro de um amor, é no planalto que quer se fixar. O planalto é o lugar que representa o seu Sul, o Sul de sua vida. 


\section{REFERÊNCIAS}

APPIAH, Kawame Anthony. Na casa de meu pai. Rio de Janeiro: Contraponto, 1997.

CHAVES, Rita. O passado presente na Literatura Angolana. In: Via Atlântica, Sáo Paulo, p. 149-161, 2004.

CHAVES, Rita; MACÊDO, Tania (org.). Portanto... Pepetela. São Paulo: Ateliê, 2009.

DUTRA, Robson. Literatura e Naçâo: Pepetela e a História de Angola. Revista de História Comparada, Rio de Janeiro, v. 5, n. 1, p. 149-178, 2011.

HALL, Stuart. A identidade cultural na pós-modernidade. Traduçăo de Tomaz Tadeu da Silva. 10. ed.. Rio da Janeiro: DP\&A, 2005.

MATA, Inocência. Pepetela e as (novas) margens da "naçăo" angolana. In: Veredas, Porto, p. 133-145, 2001.

PEPETELA. 0 planalto e a estepe. Sáo Paulo: Leya, 2009.

SANTOS, Boaventura de Sousa, Entre Próspero e Caliban: colonialismo, pós-colonialismo e inter-identidade. In: Novos estudos, p. 24-29, 2003. 